\title{
Protection of Virtual Property
}

Fengming Yang ${ }^{1,2}$

1 Faculty of Law,Zhejiang Wanli University, Ningbo, 202006, China.

2 Zhejiang Wanli University, Ningbo 315100, China.

E-mail:mail to:1787873643@qq.com.

Abstract: With the continuous innovation of life style, people's property forms are gradually diversified, virtual property is becoming the most important part of people's daily life. Although the virtual property is quite different from ordinary property forms, it still exists as a special property, and is subject to the adjustment of civil law. With the recent promulgation of Civil Code, virtual property is brought into the scope of protection of civil law, which lays the most solid foundation for the legal protection of virtual property, and points out the direction for the relevant laws of virtual property in the future.

Keywords: network virtual property, civil code, legislative protection, judicial practice.

\section{Introduction}

At present, the rapid development of the network era, the promotion of digital payment and the expansion of the game industry, is constantly innovating the modern financial industry. Network virtual property is becoming an important form of property in people's life. In the Civil Code, the protection of virtual property is clearly included in the general provisions. Yang Lixin, a famous jurist in China, defined the virtual property of the network as the digital property existing in the network space isolated from the reality, which can be measured by the existing measurement standards $^{[1]}$.

Network virtual property has absolute virtuality and negotiability, and the virtuality embodied in it is the most prominent feature of network virtual property, which results in a difficult problem of protecting network virtual property in the legal level. But its value existence also decided that we must seek the corresponding protection positively to the network fictitious property ${ }^{[2]}$. Therefore, in order to solve the legal disputes about virtual property properly, it is necessary to protect the existing virtual property by law.

\subsection{Guarantees of legislation}

Great progress has been made in the legislative protection of network virtual property. In the Civil Code recently adopted, it is clearly stipulated that: "Where the law has provisions on the protection of data and network virtual property, such provisions shall prevail." According to the current legislation and judicial practice in our country, the protection of the network virtual property can learn from the following legal provisions ${ }^{[3]}$.

First of all, after the constitution was amended in 2004, the protection of citizens' legal private property is included in the constitution, so that the network virtual property is not only the citizens' legal private property, but also fully protected by law, which lays a legislative foundation for the protection of network virtual property.

Secondly, the "Civil Code" clearly provides: "The law on data, the protection of virtual property network provisions, in accordance with its provisions. This provision of the General Rules of Civil Law provides a legal basis for the future special legislation on network virtual property and network payment. Therefore, many people in the legal community

Copyright (C) 2020 Fengming Yang

doi: 10.18282/le.v9i5.1207

This is an open-access article distributed under the terms of the Creative Commons Attribution Non-Commercial License

(http://creativecommons.org/licenses/by-nc/4.0/), which permits unrestricted non-commercial use, distribution, and reproduction in any medium, provided the original work is properly cited. 
believe that, while clarifying the protection of the rights to online virtual property, relevant laws, regulations and judicial interpretations shall be further formulated to clarify such important issues as the recognition standards, compensation standards and inheritance of online virtual property rights ${ }^{[4]}$.

Thirdly, from the point of view of criminal law, although there is no direct criminal law to protect virtual property, it is an important crime closely related to virtual property, and the crime of destroying the function of computer information system in Article 286 of the criminal law ${ }^{[5]}$.

\subsection{Protection in Judicial Practice}

At present, in the corresponding judicial trials, as there is still no perfect legal basis and legal procedure for virtual property to apply to the trial, the majority of cases can only be carried out in accordance with the judicial procedures in civil trials. The common problems are as follows:

The distribution of the burden of proof is detrimental to the owners of virtual property. The virtual property is stored on the equipment of the service provider. If the owner of the virtual property has caused the corresponding dispute over the virtual property, he will face great difficulty in obtaining evidence. The preservation of the virtual property is unilaterally in the hands of the service provider, In civil proceedings, the burden of proof is usually "whoever claims shall produce evidence". ${ }^{[6]}$ If the party claiming the corresponding right fails to provide the corresponding evidence, it shall bear the corresponding adverse consequences of the proceedings and the burden of proof in the dispute over the virtual property on the Internet.In addition, if the loss of data is due to equipment failure or other unforeseen causes, the claimants will face an embarrassing situation of unwarranted.

It is difficult to determine the value of certain network property. In the network virtual property dispute, if is the savings nature virtual property, then may act according to the corresponding factual situation and the legal standard to solve. However, if the disputed virtual property is such as virtual currency, membership, virtual props, game property and so on, it is difficult to have a common value. And the difference from the situation that the owner has used also makes the calculation of its value very difficult and different.

With the rapid development of virtual network and the rapid popularization and application of virtual property in recent years, the judicial organ has obtained the corresponding judicial experience in the unceasing judicial practice, and has provided the most valuable judicial experience and practical cases for the legislative protection and judicial protection of virtual property in the future, and will form the corresponding judicial system in the near future.

\section{Issues to be Noted in the Protection of Network Virtual Property}

The rapid development of today's society is closely related to the Internet, the Internet and cloud technology and other scientific and technological means to promote innovation, people enjoy the convenience also bear the corresponding risks ${ }^{[7]}$. The netizen and the network virtual property in our country cardinal number are big, the existence form is diverse, the existence domain is many. All these have brought corresponding problems to the protection of virtual property. We should realize that there is still a lack of corresponding measures to deal with the disputes and crimes of virtual property.

\subsection{Lack of protection in the legislation of network virtual property}

Network technology is developing, but there is a huge gap in the corresponding legal protection in our country, although there are corresponding applicable laws such as "Constitution" and "Civil Code". In a certain scope as a legal basis to solve the corresponding disputes, but the face of increasingly complex network development trends are increasingly difficult to play an excellent targeted treatment.

In the civil field, the disputes of virtual property are increasing day by day. Judicial organs should not only choose the application of virtual property within the scope of existing laws, but also jump out of the framework of civil trials in the past, combine the nature of virtual property to try disputes, and make judgments as fair and just as possible. In the criminal field, the criminal cases of virtual property are also on the rise, without a suitable law as the basis for the trial, the nature of the crime is difficult to be characterized, making the trial of the criminal cases of virtual property there are huge obstacles ${ }^{[8]}$. The lack of legislation leads to that it is difficult to apply appropriate regulations to solve disputes 
in judicial practice, which has a great impact on the progress of China's virtual property protection and its social application.

\subsection{Difficulties in the Execution of Adjudication of Virtual Property on the Internet}

The execution of the case is always the most important in the judicial practice, because the success and efficiency of the execution are directly related to the rights of the right holder can be fully protected. But at present the execution of our country fictitious property case is still a difficult problem.

Difficulties in enforcement.Virtual property is often stored in the equipment of the service provider. Therefore, in order to enforce the Virtual property, the active cooperation of the service provider is required. Otherwise, the enforcement will be difficult. Failure to enforce the Virtual property within the prescribed time limit can only be facilitated by warning and fine, and in serious cases, the corresponding person in charge may be detained.

Difficulties in property pricing. ${ }^{[9]}$ Virtual property in the enforcement, in what ways should be carried out? Is the virtual property itself? Or is it to be converted into a currency of equal value that is recognized by both sides? If you choose to enforce the virtual property, you will still face the above enforcement issues; but if you choose to enforce the equivalent value of currency recognized by both sides, how should the value of the virtual property be determined? If the parties cannot agree, should it be left to the discretion of the judge? Even if the judge does not have the corresponding professional knowledge. If this method is chosen, then what should be done with the original virtual property? Should it be destroyed or transferred to a third party in value? This is also the problem we should solve.

The execution of the case is always the most important in the judicial practice, because the success and efficiency of the execution are directly related to the rights of the right holder can be fully protected. To the parties, the belated justice is not the real justice. But as far as the execution of the virtual property case is concerned, it is still a long-term and difficult problem.

\section{Improve the Legal System for the Protection of Virtual Property}

\subsection{Perfecting and supplementing the existing civil legal provisions}

At present, it is urgent to legislate for the protection of virtual property. Making special law is the best choice for the protection of virtual property. But the procedure of legislation is complicated and long. In view of the lack of legal basis for the direct application of virtual property in our country, the most effective way is to apply it by formulating relevant judicial interpretation or adding corresponding legal content when revising or innovating the law.

\subsection{Develop a special Virtual Property Protection Act}

The most effective solution is to formulate pertinent laws to be applied to judicial practice. In legislation, we should take measures to protect the network virtual property, and the concept of virtual property should be clarified and legalized, although the legal concept of virtual property has been defined in the Civil Code. But in the civil law norm, the virtual property right should be defined as a kind of right which exists independently and has legal binding force. Its ultimate goal must make the network user's virtual property right obtain the full legal protection, divides the virtual property right into a concrete civil right. When the related virtual property dispute appears, may select the suitable clause directly accurately in the existing laws and regulations, thus effectively solves the legal dispute caused by the virtual property.

\subsection{Improve the judicial protection system for virtual property}

Jurisdiction over cases involving disputes over virtual property. With regard to the jurisdiction over disputes over virtual property, by reference to the Interpretation of the Supreme People's Court on Issues Concerning the Application of Law in the Trial of Cases Involving Copyright Disputes over Computer Network, a copyright infringement case shall be under the jurisdiction of the people's court at the place where the infringing act is committed or where the defendant is domiciled. This provision provides a reference standard for the jurisdiction of disputes over virtual property, that is, the place where the tort occurs is the location of the equipment that carries out the tort, such as network server, computer terminal, etc., and the corresponding jurisdiction is established by combining the characteristics of virtual property itself and the common constituent elements of common disputes over virtual property in society[10]. 
Judicial arbitration mechanism can be introduced in the legal way. With the rapid development of the virtual network industry in China, the disputes of virtual property on the network appear constantly, but the cases are complicated and complicated. In order to solve the disputes of virtual property on the network efficiently, we can set up the corresponding arbitration organization for the virtual property on the network and the network service, so as to effectively deal with the disputes of various kinds of virtual property on the network in the current society, so as to reduce the pressure of the judiciary To improve the efficiency of dispute resolution.

\section{References:}

1. Yang Lixin, Wang Zhonghe. Journal of National Prosecutor's College, 2004.06

2. On legal Protection of Network Virtual Property [J]. Journal of Chongqing University of Science and Technology (Social Science edition). 2010(21)

3. The meaning and important value of network virtual property stipulated in general Provisions of Civil Law [J]. Yang Lixin. Oriental Law, 201703

4. Nature identification of Network Virtual Property and Analysis of Civil Law Protection [J]. Shen Zhiming. Legal Review. 09, 2020

5. On the Legal Protection of Network Virtual Property [D]. Li Yuan. 2013, China University of Political Science and Law

6. On the Legal Property and Civil Law Protection of Virtual Property [D]. Pan Hong. China University of Political Science and Law 2010

7. Reflections on the Civil Law Protection of Network Virtual Property [J]. Journal of Yang Ling Vocational And Technical College. 02, 2020

8. Brief Analysis of Criminal Law Protection of Virtual Property [J]. Zhao Nannan. Legal Review. 18th Issue, 2020

9. Discussion on civil Law Protection of Network Virtual Property [J]. Wang Xiaoqing. Legal System and Society. 07, 2020

10. On the nature of Network Virtual Property and its Legal Protection [J]. Lu Kunrong. Legal Review.2019 01 